\title{
Obstetric and neonatal outcome in women with a history of recurrent miscarriage at tertiary care hospital, Karnataka: a retrospective cross- sectional study
}

\author{
Chintan Upadhyay ${ }^{1}$, Nisha Upadhyay ${ }^{2 *}$
}

\begin{abstract}
${ }^{1}$ Department of Obstetrics and Gynecology, ${ }^{2}$ Department of Pediatrics, GMERS Medical College and Civil Hospital, Gandhinagar, Gujarat, India
\end{abstract}

Received: 10 December 2017

Accepted: 08 January 2018

\section{*Correspondence:}

Dr. Nisha Upadhyay,

E-mail: drchintan1508@gmail.com

Copyright: (c) the author(s), publisher and licensee Medip Academy. This is an open-access article distributed under the terms of the Creative Commons Attribution Non-Commercial License, which permits unrestricted non-commercial use, distribution, and reproduction in any medium, provided the original work is properly cited.

\begin{abstract}
Background: When clinical pregnancy is established, the risk of spontaneous pregnancy loss is $\sim 12-14 \%$, and therefore the incidence of Recurrent Pregnancy Loss (RPL) by chance alone would be in the order of $0.35 \%$. It occurs in $0.5-3 \%$ of women. The objective of this study was to evaluate the obstetric outcome in pregnancies with history of one or more abortions.

Methods: It is a retrospective cross-sectional study done at Obstetrics and Gynecology Department, Dr. B. R. Ambedkar Medical College and Hospital, Bangalore. Record review of cases was done from January 2005 to December 2009. Inclusion criteria were pregnancies with history of previous abortions.

Results: There were 400 cases with previous history of abortions. There were $266(66.4 \%)$ booked cases while 134 $(33.5 \%)$ were unbooked cases. $272(68.0 \%)$ patients crossed viable period of pregnancy (more than 28 weeks). Around $56(14.0 \%)$ cases had repeat abortions, $276(69.0 \%)$ cases underwent vaginal delivery and 124 (31.0\%) underwent cesarean section. Almost $91(22.8 \%)$ of Babies were low birth weight while others were above $2.5 \mathrm{~kg}$. There were $52(13.0 \%)$ preterm babies and $28(7.0 \%)$ Intrauterine demise of fetuses.

Conclusions: Patients with previous history of abortions are at increased risk of adverse maternal and perinatal outcome.
\end{abstract}

Keywords: IUD, LBW, Perinatal outcome, Recurrent miscarriage

\section{INTRODUCTION}

Abortion is a much-debated issue regarding its physiology, pathology, elements and association with related factors. Every year, 22 million unsafe abortions are take place all over world and almost $98 \%$ unsafe abortion occur in developing countries. According to World Health Organization (WHO) report, total number of unsafe abortions has increased from about 20 million in 2003 to 22 million in 2008. ${ }^{1,2}$ Almost 10-15\% of pregnancies affected by Miscarriage before 24 completed weeks of gestation. ${ }^{3}$ When clinical pregnancy is established, the risk of spontaneous pregnancy loss is $\sim 12-14 \%$, and therefore the incidence of Recurrent Pregnancy Loss (RPL) by chance alone would be in the order of $0.35 \% 4,5$. It occurs in $0.5-3 \%$ of women. Whilst the risk of miscarriage in a subsequent pregnancy has now been well documented, the obstetric and neonatal outcomes of pregnancy which progressed beyond 24 weeks in this group of women are still far from clear. ${ }^{6-10}$

Spontaneous miscarriage occurs in $\sim 15 \%$ of all pregnancies, as recorded by hospital episode statistics. The actual figure, from community-based assessment, 
may well be higher than this as some women miscarry at home and remain unreported to hospital. Between 1 and $2 \%$ of fertile women will experience recurring pregnancy loss and despite a wide range of investigations, no apparent cause can be found in $\sim 50 \%$ of cases. ${ }^{11}$

Recurrent loss of pregnancy is distressing for the patient and frustrating for the clinician, especially where treatment options are limited as in idiopathic recurrent miscarriage. The mainstay of management of these patients is empirically based upon tender loving care and emotional support. In the absence of predicted success rates with idiopathic recurrent miscarriage, the clinician is at a disadvantage in the miscarriage clinic setting, where the most commonly posed question concerns the chance of future pregnancy success. Previous population studies are small, and few have documented sufficient patient numbers to generate confidence with clinical prediction of future pregnancy outcome, in terms of success or failure. The effect of emotional support, supplemented by ultrasound in early pregnancy gives 'success rates' of between 70 and $80 \% .{ }^{11}$ So present study was conducted with the objectives of to evaluate the obstetric outcome in pregnancies with history of one or more abortions.

\section{METHODS}

This retrospective cross-sectional study was done among 800 pregnant women visited at Department of Obstetrics and Gynecology in Dr. B. R. Ambedkar Medical College and Hospital, Bangalore during January 2005 to December 2009.

800 pregnant women of age 18 to 40 years of whom 400 women (Group - 1) had history of two or three abortions and 400 women (Group - 2) had no history of abortions were enrolled in the study. Hospital records has been checked and the outcome of pregnancy like preterm birth, very preterm birth, ectopic pregnancy, abortion, intrauterine death and birth weight of the babies in those reaching full term were recorded to note the occurrence of low and very low birth weight. Age, parity, pregnancy outcome, mode of delivery, birth weight and indications for cesarean were noted. History of medical disorders: hypertension, diabetes mellitus, heart disease, renal disorders, autoimmune diseases, multiple gestations, history of gestational trophoblastic diseases. This was all exclusion criteria for the study.

Data collection was done after ethical permission from institutional ethical committee and informed consent of clients. Pre-tested questionnaire was administered and details like socio-demographic information, past history of medical illness, menstrual history was collected. The baseline data recorded in all patients were maternal age, period of gestation, mode of delivery, maternal and fetal outcome. These factors were compared between two study group.
Data was cleaned, validated and analyzed on the Epi info 7. For continuous variables range, mean and standard deviation was calculated and for categorical variables proportion and percentage was obtained. To know the association between dependent and independent variables chi-square was applied accordingly. $\mathrm{P}$ value less than 0.05 was considered as statistically significant.

\section{RESULTS}

Table 1 shows that study included $66.5 \%$ cases and $80.0 \%$ controls as registered cases. Almost $44.8 \%$ and $36.5 \%$ study participants from cases and control groups respectively were belonged to age group 20 to 25 years and difference between age group was statistically significant ( $\mathrm{p}<0.05$ ). Almost $19.3 \%$ and $11.3 \%$ participants of cases and control respectively have low birth weight baby $(<2.5 \mathrm{~kg})$ and $50.8 \%$ and $61.8 \%$ babies were belonged to normal birth weight group respectively and difference between birth weight of both the groups were statistically significant $(\mathrm{p}<0.05)$.

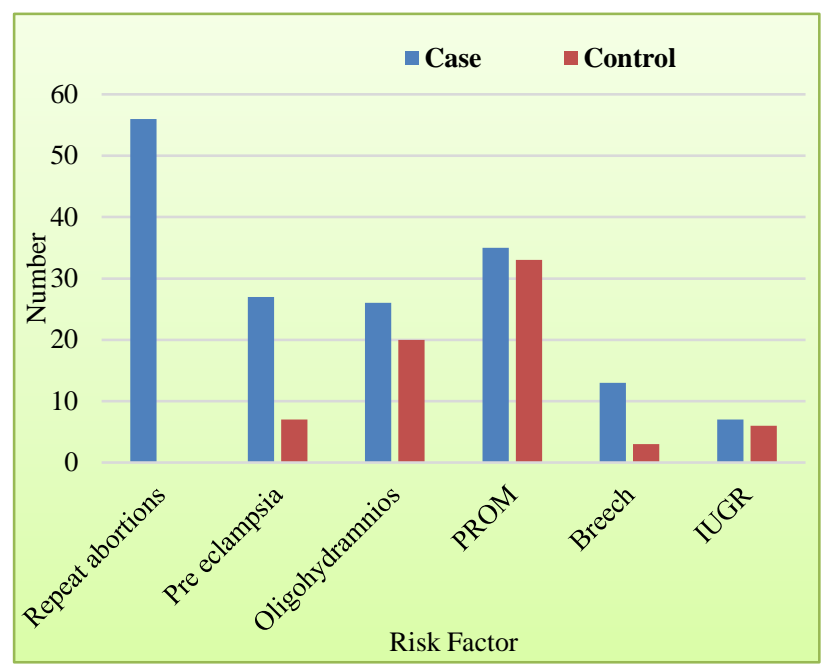

PROM: Premature Rupture of Membrane; IUGR: Intra-uterine Growth Retardation

Figure 1: Risk factor present in study population.

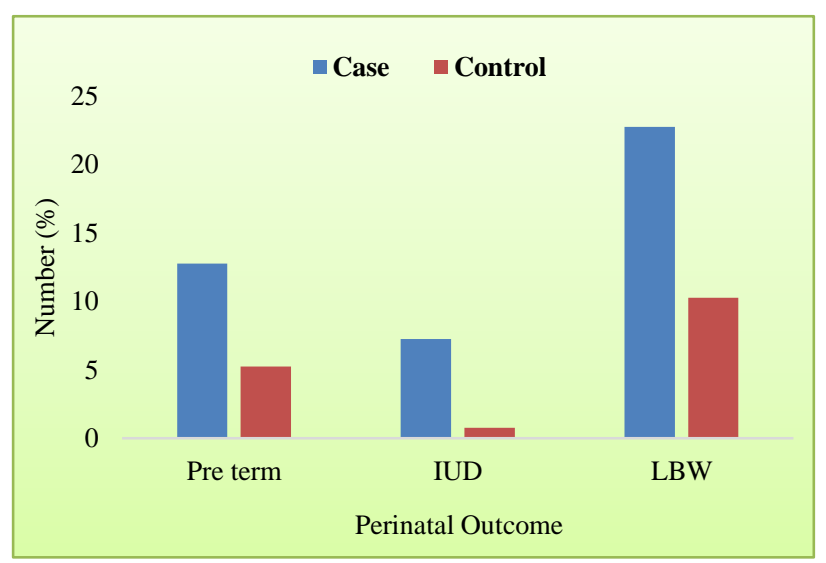

IUD: Intra-uterine Death; LBW: Low Birth Weight

Figure 2: Perinatal outcome in study population. 
Around $32.0 \%$ and $21.0 \%$ participants from case and control group have period of gestation was between 28 to 37 week and difference between gestation period of both the groups were statistically significant $(\mathrm{p}<0.05)$. Almost $69.0 \%$ and $72.3 \%$ deliveries of case and control group respectively were vaginal delivery and difference between mode of delivery of both the groups were statistically not significant $(\mathrm{p}>0.05)$. Indication of LSCS was previous LSCS, PIH, oligohydramnios, breech, PROM, RH -ve and IUGR respectively in group of cases.

Table 1: Clinical-demographic characteristics of participants $(\mathrm{N}=800)$.

\begin{tabular}{|c|c|c|c|}
\hline Parameters & $\begin{array}{l}\text { Group } 1 \\
\text { (case } \\
\text { group) }\end{array}$ & $\begin{array}{l}\text { Group } 2 \\
\text { (control } \\
\text { group) }\end{array}$ & P value \\
\hline \multicolumn{4}{|l|}{ Case } \\
\hline Registered & $266(66.5)$ & $320(80.0)$ & \multirow{2}{*}{$<0.001$} \\
\hline Un-registered & $134(33.5)$ & $80(20.0)$ & \\
\hline \multicolumn{3}{|l|}{ Age (in years) } & \multirow{5}{*}{$<0.001$} \\
\hline $18-20$ & $89(22.2)$ & $123(30.8)$ & \\
\hline $20-25$ & $179(44.8)$ & $146(36.5)$ & \\
\hline $25-30$ & $76(19.0)$ & $92(23.0)$ & \\
\hline$>30$ & $56(14.0)$ & $39(9.8)$ & \\
\hline \multicolumn{3}{|l|}{ Parity } & \multirow{5}{*}{$<0.01$} \\
\hline 0 & $27(6.7)$ & $315(78.4)$ & \\
\hline 1 & $186(46.5)$ & $45(11.8)$ & \\
\hline 2 & $131(32.1)$ & $28(7.6)$ & \\
\hline$\geq 3$ & $56(14.7)$ & $12(2.2)$ & \\
\hline \multicolumn{3}{|c|}{ Birth Weight (in Kg) } & \multirow{5}{*}{$<0.001$} \\
\hline$<2.5$ & $77(19.3)$ & $45(11.3)$ & \\
\hline $2.5-3$ & $203(50.8)$ & $247(61.8)$ & \\
\hline $3-3.5$ & $84(21.0)$ & $89(22.3)$ & \\
\hline$>3.5$ & $36(9.0)$ & $19(4.8)$ & \\
\hline \multicolumn{3}{|c|}{ Period of gestation (in week) } & \multirow{4}{*}{$<0.001$} \\
\hline $28-37$ & $128(32.0)$ & $84(21.0)$ & \\
\hline $38-40$ & $264(66.0)$ & $302(75.5)$ & \\
\hline$>40$ & $8(2.0)$ & $14(3.5)$ & \\
\hline \multicolumn{3}{|l|}{ Mode of delivery } & \multirow{3}{*}{0.3} \\
\hline Vaginal & $276(69.0)$ & $289(72.3)$ & \\
\hline LSCS & $124(31.0)$ & $111(27.8)$ & \\
\hline \multicolumn{3}{|c|}{ Indication for LSCS } & \multirow{8}{*}{$<0.001$} \\
\hline Previous LSCS & $28(7.0)$ & $27(6.8)$ & \\
\hline $\mathrm{PIH}$ & $15(3.8)$ & $7(1.8)$ & \\
\hline Oligohydramnios & $11(2.8)$ & $20(5.0)$ & \\
\hline Breech & $7(1.8)$ & $3(0.8)$ & \\
\hline PROM & $13(3.3)$ & $3(0.8)$ & \\
\hline Rh -ve & $6(1.5)$ & $20(5.0)$ & \\
\hline IUGR & $4(1.0)$ & $7(1.8)$ & \\
\hline \multicolumn{3}{|l|}{ Gender } & \multirow{3}{*}{0.08} \\
\hline Male & $228(57.0)$ & $203(50.8)$ & \\
\hline Female & $172(43.0)$ & $197(49.3)$ & \\
\hline
\end{tabular}

Figure 1 shows risk factor present among study population. Risk factor like repeated abortions, preeclampsia, oligohydramnios, PROM, Breech position and IUGR more in cases than controls.
Figure 2 shows that adverse perinatal outcome like preterm delivery, IUD and LBW were seen more among cases than controls and this association was statistically significantly $(\mathrm{p}<0.05)$.

\section{DISCUSSION}

In comparison with women with a previous successful pregnancy, our data suggest that women with an initial miscarriage have an increased risk of some obstetric complications. These include pre-eclampsia, threatened miscarriage, nonspecific antepartum hemorrhage, and induced labour, instrumental delivery. They are also more prone to preterm delivery, malpresentation and low birth weight.

In present study, highest number of participants were belonged to age group of 20 to 25 years and these findings are correlated with the similar study done by Annapurma $\mathrm{P}$ et al. ${ }^{12}$ Parity, pregnancy outcome observations were also comparable with the similar study done by Annapurna $\mathrm{P}$ et al, Zhou W et al and Moreau C et al. ${ }^{12-14}$ Present study observed low birth weight in $19.9 \%$ cases who had a history of abortion and this findings are not correlate with the similar study done by Annapurna $\mathrm{P}$ et al and Basso $\mathrm{O}$ et al. ${ }^{12-15}$

Present results show that any pregnancy following an initial miscarriage is associated with a degree of increased obstetric and perinatal risk. This study questions the evidence behind the attribution of risk only to women who have had three or more consequent miscarriages (recurrent miscarriage). At the same time, the magnitude of this risk is likely to be small as women with a history of recurrent miscarriage achieve good pregnancy outcomes with support from an early pregnancy unit.

In one of the study, Kashanian $\mathrm{M}$ et al found that there is risk of repeat abortion (16.5\%), fetal death (1.5\%) and rate of cesarean section $(28.1 \%)$ were increased in previous miscarriage cases. ${ }^{16,17}$ In the present study we also found same results. Study done by Jivraj et al found that rates of preterm delivery $(13 \%)$, perinatal loss $2.5 \%$ and caesarean section $(36 \%)$ were significantly high. ${ }^{19}$ In one of the previous study Bhattacharya et al, stated that miscarriage group faced a higher risk of pre-eclampsia $(4.4 \%)$, threatened abortion $(27.1 \%)$, rate of caesarean section $(4.2 \%)$, preterm delivery $(9.2 \%)$ and low birth weight $(8.5 \%) .{ }^{14}$ Incidence of high risk factors were also increased in our study as described in above results

\section{CONCLUSION}

Women with an initial miscarriage are at increased risk of some obstetric and perinatal complications in comparison with women who have a successful initial pregnancy. The risks of pre-eclampsia, PROM, oligohydramnios, rate of caesarean section, preterm delivery, repeated miscarriage, low birth weight, operative interference and IUD are 
higher in women with an initial miscarriage. Therefore, patients with recurrent miscarriage represent of population at high risk of obstetric problems and close surveillance during the antenatal period is required.

Funding: No funding sources

Conflict of interest: None declared

Ethical approval: The study was approved by the Institutional Ethics Committee

\section{REFERENCES}

1. Bricker L. Types of pregnancy loss in recurrent miscarriage. Human Reprod. 2002;17(5),1345-50.

2. Policy guidance for health system: WHO, 2nd edition; 2012;1:17.

3. Wilcox AJ, Weinberg CR, O'Connor JF, Baird DD, Schlatterer JP, Canfield RE, et al. Incidence of early loss of pregnancy. N Engl J Med. 1988;319:189-94.

4. Miller JF, Williamson E, Glue J, Gordon YB, Grudzinskas JG, Sykes A. Fetal loss after implantation: a prospective study. Lancet. 1980;2:554-6.

5. Edmonds DK, Lindsay KS, Miller JF, Williamson E, Woods PJ. Early embryonic mortality in women. Fertil Steril. 1982;38:447-53.

6. Daya S. Evaluation and management of recurrent spontaneous abortion. Curr Opin Obstet Gynecol. 1993;8:188-92.

7. Tulppala M, Palosuo T, Ramsay T. A prospective study of 63 couples with a history or recurrent spontaneous abortion: contributing factors and outcome of subsequent pregnancies. Hum Reprod. 1993;8:764-70.

8. Katz YL, Kuller JA. Recurrent miscarriage. Am J Perinatol. 1994;11:386-97.

9. Quenby SM, Farquharson RG. Predicting recurring miscarriage: what is important? Obstet Gynecol. 1993;82:132-8.

10. Clifford K, Rae R, Regan L. Future pregnancy outcome in unexplained recurrent first trimester miscarriage. Hum Reprod. 1997;12:387-9.
11. Brigham SA, Conlon C, Farquharson RG. A longitudinal study of pregnancy outcome following idiopathic recurrent miscarriage. Hum Reprod. 1999;14(11):2868-71.

12. Annapurna P, Devi B, Devi BK. Pregnancy outcome following abortion. $\mathrm{J}$ of Evidence Based Med and Healthcare. 2015;2(41):6992-7002.

13. Zhou W, Sorensen HT, Olsena J. Induced abortion and low birthweight in the following pregnancy. Int $\mathbf{J}$ of Epidemiol. 2000;29:100-6.

14. Moreau C, Kaminski M, Ancel PY, Bouyer J, Escande B, Thiriez G, et al. Previous induced abortions and the risk of very preterm delivery: results of the EPIPAGE study. BJOG. 2005;112:4307.

15. Basso O, Oslen J, Christensen K. Risk of preterm delivery, low birthweight and growth retardation following spontaneous abortion: a registry based study in Denmark. Int J Epidemiol. 1998;27:642.

16. Kashanian M, Akbarian AR, Baradaran $H$, Shabandoust SH. Pregnancy outcome following a previous spontaneous abortion (miscarriage). Gynecol Obstet Invest. 2006;61:167-70.

17. Jivraj S, Anstie B, Cheong YC, Fairlie FM, Laird $\mathrm{SM}$, Li TC. Obstetric and neonatal outcome in women with a history of recurrent miscarriage: a cohort study. oxford journals. 2000;16(1):102 - 106.

18. Bhattacharya S, Townend J, Shetty A, Campbell D, Bhattacharya S. Does miscarriage in an initial pregnancy lead to adverse obstetric and perinatal outcomes in the next continuing pregnancy?. BJOG 2008;115(13):1623-9.

Cite this article as: Upadhyay $\mathrm{C}$, Upadhyay N. Obstetric and neonatal outcome in women with a history of recurrent miscarriage at tertiary care hospital, Karnataka: a retrospective cross-sectional study. Int J Reprod Contracept Obstet Gynecol 2018;7:648-51. 